\title{
Acoustic Compaction Layer Detection
}

\author{
T. E. Grift, M. Z. Tekeste, R. L. Raper
}

\begin{abstract}
The ASAE standardized tool to detect the depth and strength of compaction layers in the field is the cone penetrometer. Since this method is point-to-point, researchers have experimented with on-the-fly alternatives that can be used as, or in combination with, a standard tillage tool. On-the-fly compaction layer sensing also enables adaptive tillage, where the soil is only tilled as deep as necessary, which can lead to significant energy savings and erosion reduction. Wedged tips, strain gauges mounted on a deflecting tine, air bubbles pushed into the soil, as well as ground-penetrating radar have been tested for this purpose. In this research, passive acoustics was used to detect the compaction layer by recording the sound of a cone being drawn through the soil. The premise was that a more compacted layer should cause higher sound levels, which might reveal the depth and strength of the compaction layer. Two experiments were conducted in the soil bins of the USDA-ARS National Soil Dynamics Laboratory in Auburn, Alabama. First, constant-depth tests (15 and $30 \mathrm{~cm}$ ) at three compaction levels $(0.72,2.8$, and $3.6 \mathrm{MPa})$ revealed the relationship of sound amplitude with depth and compaction. Second, to test the detection capability, the cone was gradually inserted in the soil, passing through an artificial compaction layer. A windowed, short-time Fourier transform (STFT) analysis showed that the compaction layer is detectable since the sound amplitude was positively related to depth and compaction levels, but only in the highest frequency range of the spectrum. This led to the conjecture that the soil-cone interface acts as a low-pass filtering mechanism, where the cutoff frequency becomes higher in the compaction layer due to a more intimate contact between sensor and soil.
\end{abstract}

Keywords. Plow pan, Precision tillage.

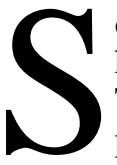
oil compaction, caused by either natural causes or human interference, is a major yield-limiting factor. This is because soil compaction: (1) reduces soil pore size, (2) changes pore size distribution, (3) increases soil strength, (4) reduces air and water permeability, (5) increases heat capacity and bulk density, and most importantly, (6) increases root penetration resistance (Al-Adawi and Reeder, 1996). Distinctively high-strength soil layers are commonly termed "hardpans" or "plow soles." Hardpans impede plant roots from uptake of nutrients and soil water reserves in the deeper soil strata. They also decrease water infiltration, which can accelerate loss of nutrients due to erosion and runoff. Under wet conditions, roots above the hardpan layer may suffocate due to water logging. The overall deterioration of soil quality due to compaction can result in a decrease of crop productivity and may increase the cost of fertilization.

Hardpan properties are not uniform across the field, but vary in depth and strength due to soil and crop factors, as well as farming and tillage practices (Clark, 1999; Fulton et al.,

Article was submitted for review in June 2004; approved for publication by the Soil \& Water Division of ASABE in July 2005.

The use of company names does not indicate endorsement by the University of Illinois, University of Georgia, or USDA-ARS.

The authors are Tony E. Grift, ASABE Member Engineer, Assistant Professor, Department of Agricultural and Biological Engineering, University of Illinois at Urbana-Champaign, Urbana, Illinois; Mehari Tekeste, ASABE Student Member, Graduate Research Assistant, Department of Biological and Agricultural Engineering, University of Georgia, Athens, Georgia; and Randy L. Raper, ASABE Member Engineer, Agricultural Engineer, Lead Scientist, USDA-ARS National Soil Dynamics Laboratory, Auburn, Alabama. Corresponding author: Tony E. Grift, 1304 W. Pennsylvania Ave., Urbana, IL 61801; phone: 217333-2854; fax: 217-244-0323; e-mail: grift@uiuc.edu.
1996; Raper et al., 2001). Farmers often practice conventional subsoiling to mechanically disrupt the hardpan layer. This is done by adjusting the depth of the subsoiling implement at a uniform level, based on observational judgment and/or cone index measurements. Due to the depth variability of the hardpan, this means either that the compaction layer is not disrupted at all or that energy is wasted by tilling deeper than necessary. A "site-specific tillage scheme," where the tillage depth was adapted to the hardpan location, was investigated by Raper et al., (2003) and was found to yield energy savings of $25 \%$ compared to conventional tillage while the yield of corn (Zea mays L.) remained unaffected.To realize sensorbased, variable-depth subsoiling, instrumentation is needed that accurately measures the location of the hardpan and conveys this information to an actuation mechanism. Mapbased variable-depth subsoiling can then be implemented by adding positioning functionality such as a GPS.

Soil cone penetrometers, as standardized according to ASAE Standard S313.3 (ASAE Standards, 1999a), measure the soil penetration resistance as a function of depth to assess soil strength. The result is reported as the cone index (CI) according to ASAE Standard EP 542 (ASAE Standards, $1999 \mathrm{~b})$. The cone index is defined as the force required to insert the penetrometer probe into the soil divided by the cone base area. Raper et al., (1999) developed a tractor-mounted, multiple-probe soil cone penetrometer (MPSCP) with the capability of obtaining a set of five cone index measurements in a single insertion to improve the data acquisition speed. A major drawback of the cone penetrometer method is that it is strongly affected by other soil factors, such as water content, bulk density, and soil type (Ayers and Perumpral, 1982; Perumpral, 1987; Raper et al., 1999; Utset and Cid, 2001). Since the cone index measurement is based on vertical insertion of the probe, a stop-and-go sampling procedure is 
currently employed. This makes the procedure time consuming and difficult to implement in a continuous sensor-based variable-depth tillage practice. An alternative, as developed by Hall and Raper (2005), is termed the On-the-go Soil Strength Sensor (OSSS). This method used a wedge-shaped tip that was drawn horizontally through the soil, and the measured force on the tip resulted in the mechanical penetration resistance as a function of depth. The study reported that the wedge index (defined as the force divided by the wedge base area, similar to cone index) was less sensitive to water content variations than the standard cone penetrometer, and the data appeared to be correlated to bulk density and cone index. Chung and Sudduth (2003) have further explored the idea of using multiple horizontal penetrometers to estimate soil mechanical resistance at five depths. Adamchuk et al. (2001) used an array of strain gauges attached to the backside of a vertical smooth blade to measure soil mechanical resistance at three depth intervals.

In this study, an alternative on-the-fly approach to hardpan location measurement was developed, based on measuring the sound level produced by a cone-shaped tip being drawn through the soil. Acoustics has been applied before to measure texture among four soil types (Liu et al., 1993). Oelze et al. (2002) measured the sound propagation velocity in soils and determined soil surface roughness using acoustic backscatter (Oelze et al., 2003).

In contrast to the on-the-fly methods discussed, the acoustic sensor (microphone) can be very small, which allows embedding into production tillage tines. In addition, since this study uses sound in the audible range $(20 \mathrm{~Hz}$ to $20 \mathrm{kHz}$ ), inexpensive microphones can be used as a sensor. The premise behind the acoustic plow pan detection method was that the produced sound level is related to: (1) soil density, since more particles sliding across the cone surface will likely produce more sound, and (2) soil strength, since more energy is required to break up harder aggregates, also resulting in higher sound levels. Although water content was expected to have an effect on the acoustic measurement, it was kept constant and is recommended as a future research extension.

The objective of this study was to investigate whether a passive acoustic method is capable of detecting the location and strength of a hardpan under constant soil water levels.

\section{Materials ANd Methods}

\section{Acoustic Measurement System}

The measurement system consisted of a tine with a cone containing a standard $8 \mathrm{~mm}$ condenser microphone (model 189958, Jameco Electronics, Belmont, Cal.) with a frequency range from $20 \mathrm{~Hz}$ to $20 \mathrm{kHz}$. The tine, cone, and microphone mounting are shown in figure 1.

The tine has a sharp front edge, and the cone was mounted on a shaft that was bolted onto the tine. The shaft is hollow, which allows the electrical connections of the microphone to be passed through and fed upward through a protective conduit welded on the back of the tine. The microphone was mounted in rubber grommets to minimize contact sound transmitted through the tine. The data acquisition was performed using a portable computer with a built-in sound card controlled by MatLab's (2000) data acquisition toolbox. The sampling rate was set to 22,050 samples/second.

\section{EXPERIMENTS}

Before experiments in the soil, a dry run in air was made to obtain an indication of the noise that was detected by the

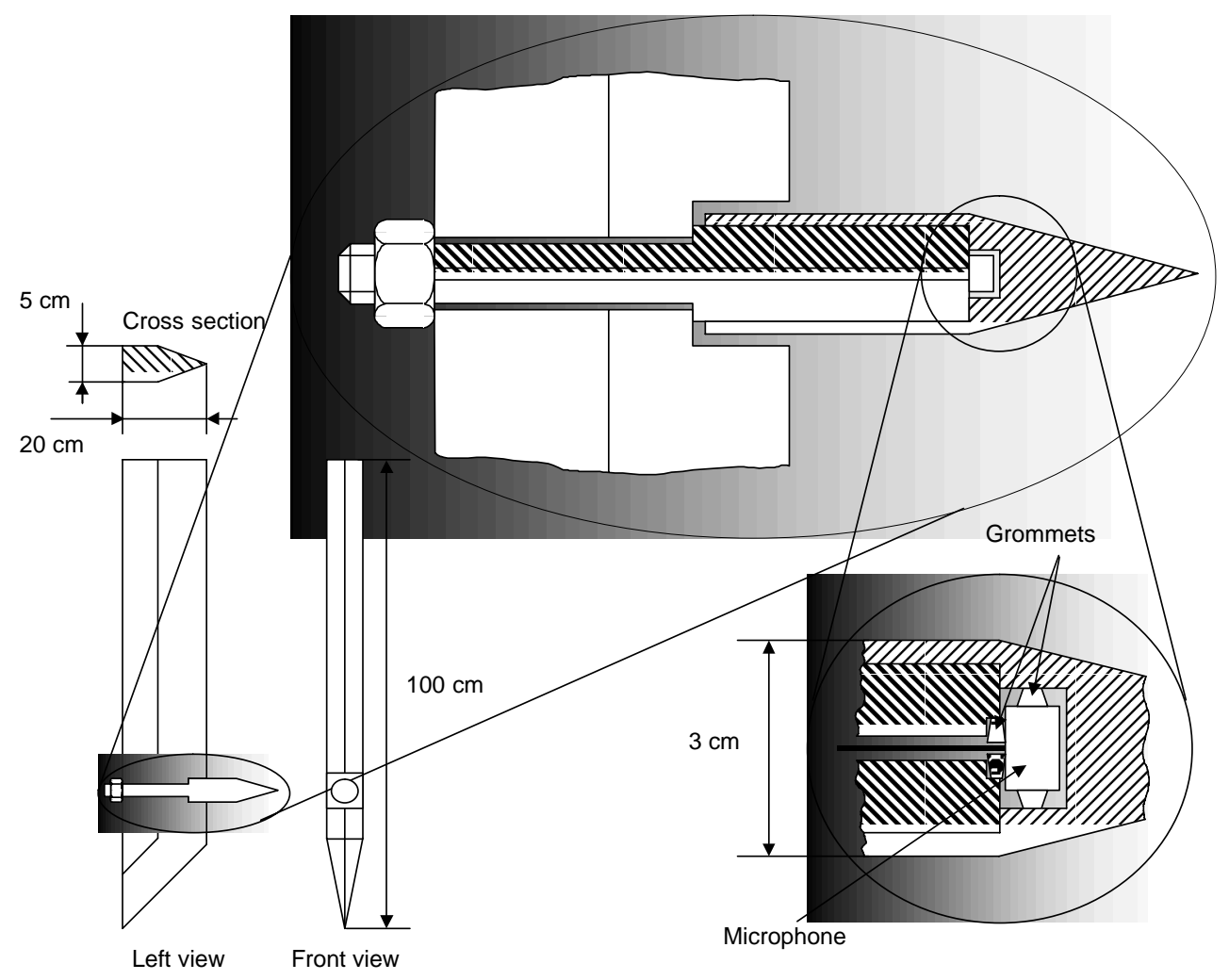

Figure 1. Tine (left) with mounted cone (top) and microphone in grommets (bottom right). 


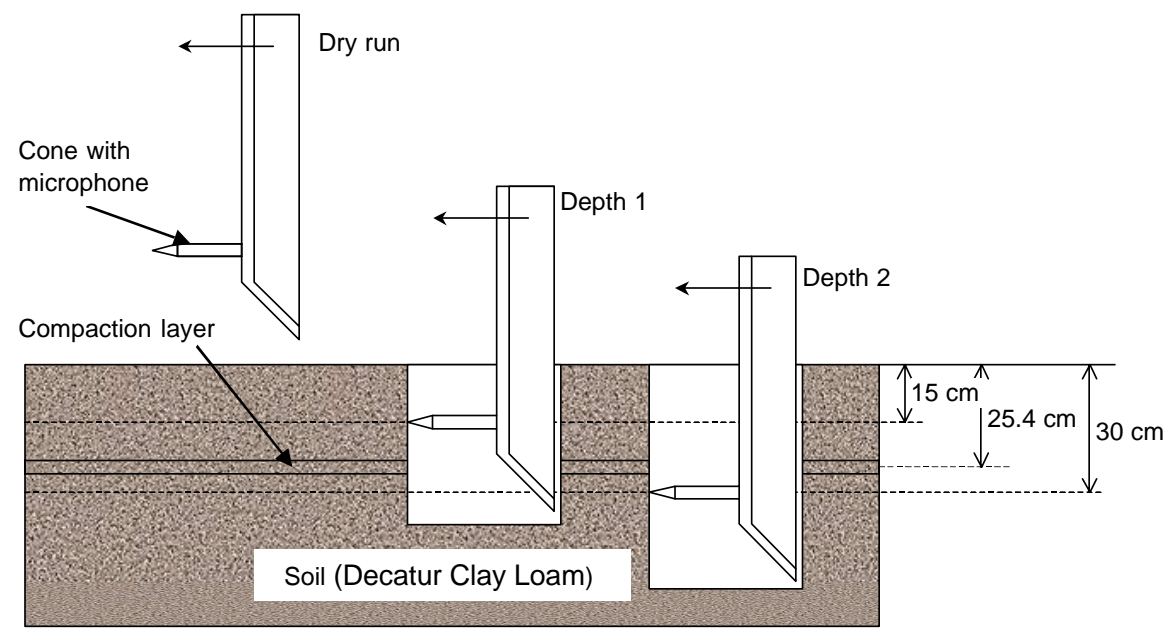

Figure 2. Constant-depth experimental arrangement, showing the two cone depths (15 and $30 \mathrm{~cm})$ and the location of the compaction layer.

microphone due to the tractor that drove the measurement cart. This was thought to be a good starting point for filtering the noise that would propagate into the soil. During all experiments, the forward speed of the tine was kept constant at $0.44 \mathrm{~m} / \mathrm{s}$. To study the effects of depth and density on the acoustic signals, constant-depth experiments were carried out at 15 and $30 \mathrm{~cm}$ with a compaction layer located at $25.4 \mathrm{~cm}$ depth (fig. 2).

Before the start of the constant-depth experiments, a hole was dug and the sensor was lowered to the desired depth. The duration of the constant-depth experiments was $20 \mathrm{~s}$, covering a distance of approx. $8.8 \mathrm{~m}$.

To test whether the acoustic method is capable of detecting the location of a compaction layer, variable-depth experiments were conducted by starting the cone at the surface, followed by a gradual penetration into the soil, through the compaction layer, until a depth of $30 \mathrm{~cm}$ was reached (fig. 3).

The compaction layer was installed at a depth of $25.4 \mathrm{~cm}$, and consequently the highest peaks in sound amplitude were expected towards the end of the run. The duration of the variable-depth experiments was $30 \mathrm{~s}$, covering a distance of approx. $13.2 \mathrm{~m}$.

\section{Soil Preparation}

Experiments were conducted in a Decatur clay loam (rhodic Paleudults) soil bin located at the USDA-ARS National Soil Dynamics Laboratory in Auburn, Alabama. The soil bins are $7 \mathrm{~m}$ wide, $58 \mathrm{~m}$ long, and $1.5 \mathrm{~m}$ deep. The soil consisted of $26.9 \%$ sand, $43.4 \%$ silt, and $29.7 \%$ clay (Batchelor, 1984). The soil was wetted and mixed with a rotary tiller so that the entire soil bin attained a uniform soil water level. Three soil density levels were created by varying the number of times a compression wheel was used. "Single pass" density amounted to a forward and backward movement of a rigid wheel on the soil. For the "double pass" density, the "single pass" procedure was repeated. For the plots with "single pass" and "double pass" conditions, a hardpan was installed at a target depth of $25.4 \mathrm{~cm}$. For the "no pass" density, no hardpan was installed. Finally, the soil surface was leveled using a blade. The soil bin was divided into two blocks, each consisting of three $12 \times 4 \mathrm{~m}$ plots. Each plot was further divided into two equal subplots. Half of the subplots were used for variable-depth experiments, and the remaining half for the 15 and $30 \mathrm{~cm}$ constant-depth experiments (fig. 4).

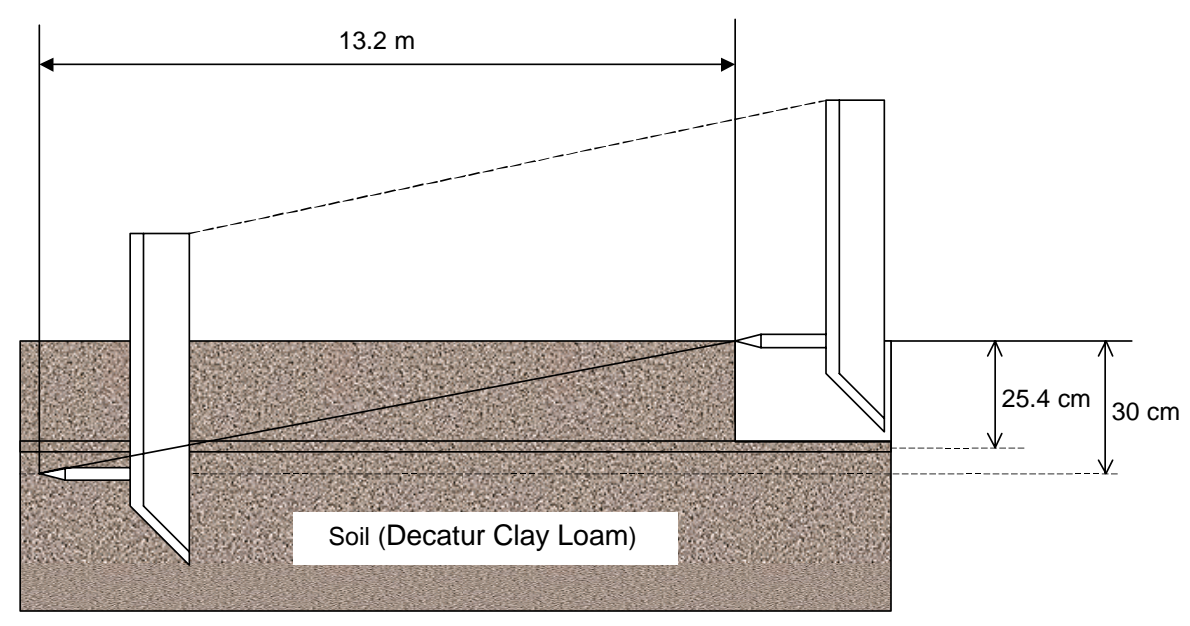

Figure 3. Variable-depth experimental arrangement, showing the sensor's gradual soil penetration. 


\begin{tabular}{||l||c||c||c||}
\hline $30 \mathrm{~cm}$ & $15 \mathrm{~cm}$ & $30 \mathrm{~cm}$ & \multicolumn{2}{|c||}{ Variable Depth } \\
\hline Variable Depth & Variable Depth & $30 \mathrm{~cm}$ & $15 \mathrm{~cm}$ \\
\hline
\end{tabular}

\begin{tabular}{|c|c|c|c|c|c|}
\hline $30 \mathrm{~cm}$ & $15 \mathrm{~cm}$ & \multicolumn{2}{|c|}{ Variable Depth } & \multicolumn{2}{|c|}{ Variable Depth } \\
\hline \multicolumn{2}{|c|}{ Variable Depth } & $15 \mathrm{~cm}$ & $30 \mathrm{~cm}$ & $30 \mathrm{~cm}$ & $15 \mathrm{~cm}$ \\
\hline
\end{tabular}

\section{No Pass $\square$ Single Pass $\square$ Double Pass}

Figure 4. Experimental plot design for the constant-depth $(15$ and $30 \mathrm{~cm})$ and variable-depth experiments and density treatments (no pass, single pass, and double pass).

Table 1. Dry bulk density, soil water content, peak cone index and depth to peak cone index.

\begin{tabular}{|c|c|c|c|c|c|c|}
\hline \multirow[b]{2}{*}{ Density } & \multicolumn{2}{|c|}{ Dry Bulk Density $\left(\mathrm{g} / \mathrm{cm}^{3}\right)$} & \multicolumn{2}{|c|}{ Soil Water Content $(\% \mathrm{w} / \mathrm{w})$} & \multicolumn{2}{|c|}{ Peak Cone Index (CI) } \\
\hline & Above Hardpan & Within Hardpan & Above Hardpan & Within Hardpan & $\mathrm{CI}(\mathrm{MPa})$ & Depth $(\mathrm{cm})$ \\
\hline No pass & 1.16 & 1.18 & 9.5 & 12.6 & 0.72 & 25.5 \\
\hline Single pass & 1.19 & 1.47 & 10.1 & 13.1 & 2.8 & 26.3 \\
\hline Double pass & 1.14 & 1.65 & 10.5 & 12.8 & 3.6 & 25.5 \\
\hline
\end{tabular}

\section{RESULTS AND DisCUSSION}

Before experimentation, the dry bulk density, soil water content (in and above the hardpan), as well as the peak cone index value and corresponding location were measured (table 1). The table entries are averages of five sampling repetitions.

From table 1 it is clear that dry bulk density did not vary appreciably for the "no pass" condition, since no hardpan was installed (the measurement was taken at $25.4 \mathrm{~cm}$, where the hardpan was installed for the "single pass" and "double pass" conditions). In the "single pass" and "double pass" conditions, however, a major increase in dry bulk density was observed due to compaction. The soil water content level was measured using a gravimetric method with oven drying at $105^{\circ} \mathrm{C}$ for $72 \mathrm{~h}$. The water content levels in the hardpan were consistently higher than above it, which was attributed to a drying effect from the surface soil downward. Since the soil water differences overall are small, this implies that the soil strength variability is mainly dictated by the bulk density. The cone index values were obtained using a cone penetrometer (Rimik, Agridry Rimik Pty, Ltd., Toowomba, Australia). As expected, the peak values were found close to the hardpan location of $25.4 \mathrm{~cm}$.

\section{CONSTANT-DEPTH EXPERIMENTS}

Figure 5 shows the fast Fourier transform (FFT) of a typical signal produced when the tine was drawn through the soil at $15 \mathrm{~cm}$ depth and no compaction layer was installed

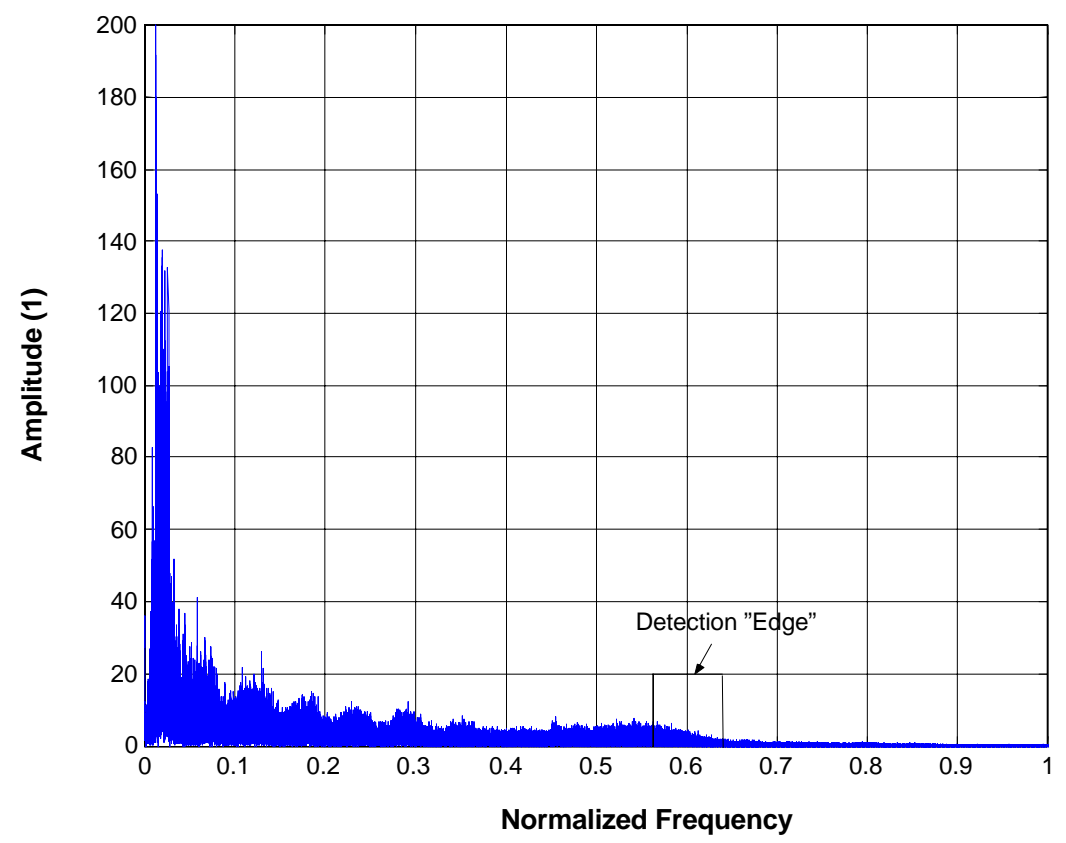

Figure 5. Acoustic signal amplitude vs. normalized frequency for constant depth $(15 \mathrm{~cm})$ and "no pass" density, with the detection edge at approximately $0.6(6600 \mathrm{~Hz})$. 

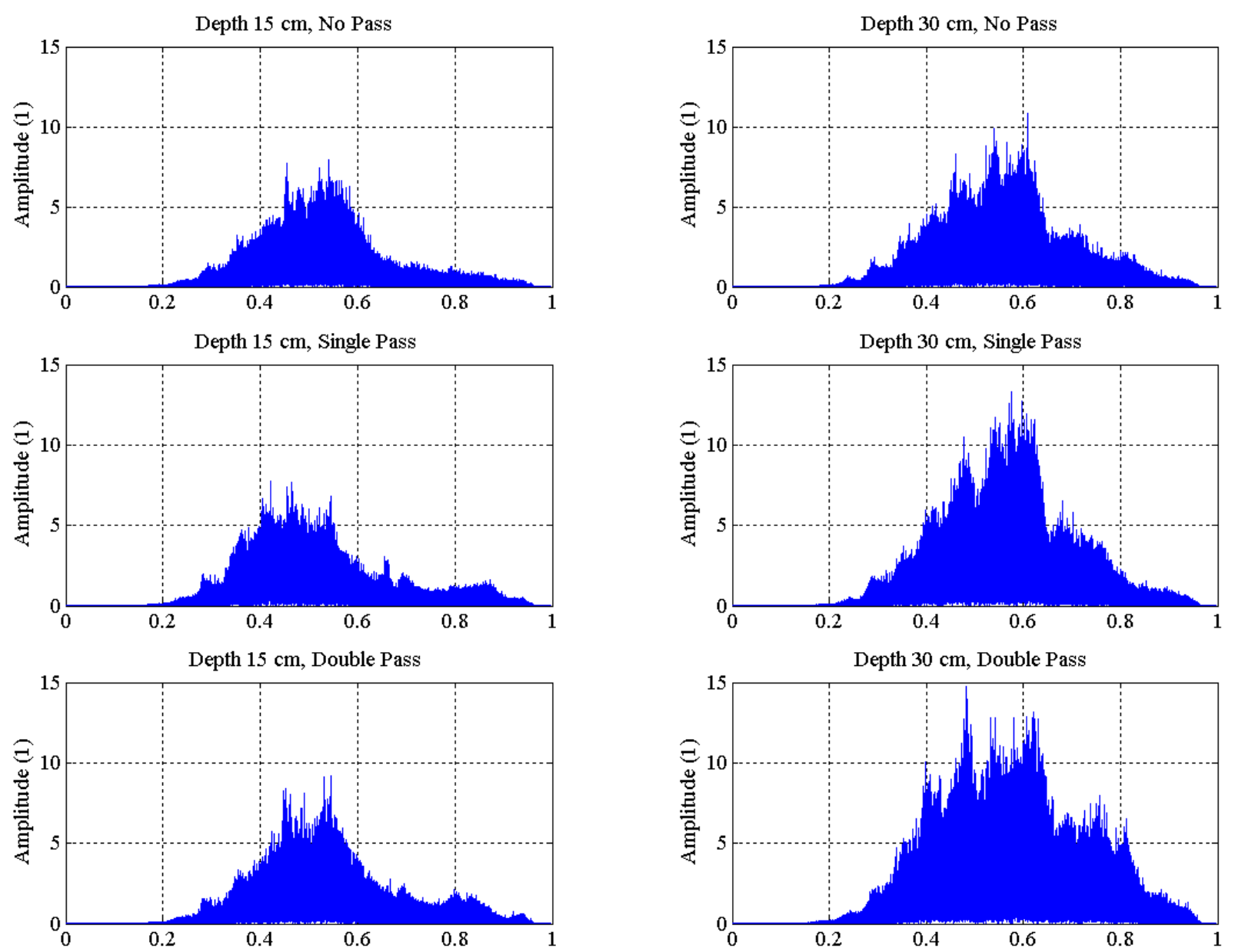

Figure 6. Comparison of depth effect (left plots $=15 \mathrm{~cm}$, right plots $=30 \mathrm{~cm}$ ) and density effect (top row $=$ no pass, center row $=$ single pass, and bottom row $=$ double pass) on acoustic signal Fourier transform.

("no pass"). The $x$-axis (frequency) is scaled from 0 to 1 , where 1 represents the Nyquist frequency $(11,025 \mathrm{~Hz})$. The sound amplitude is expressed in artificial units since the true microphone output sensitivity was unknown, combined with the unknown attenuation factors of the soil-metal-air interface of the cone itself.

The frequency spectrum shows a dominant peak in the lower range and several higher-order harmonics. The main peaks below $0.3(3300 \mathrm{~Hz})$ were also visible in the dry run data; these were caused by the tractor that drove the measurement cart.

After conducting constant-depth experiments at 15 and $30 \mathrm{~cm}$, and studying the raw data similar to figure 5 , it was discovered that differences among treatments always occurred in the highest range of the spectrum (in the range 0.57 to 0.63 , or 6,300 to $7,000 \mathrm{~Hz}$ ). This range was termed the "detection edge" and led to the conjecture that higher-frequency signals are always present, but they transfer into the microphone only when there is a more intimate contact between the cone and the medium, such as in a compaction layer. This inherent low-pass filtering mechanism causes higher-frequency signals for higher densities and higher soil strength. The detection edge range was used for filtering in the variable-depth experiments.

Six constant-depth experiments were carried out to study relationships among two depths and three treatments ("no pass," "single pass," and "double pass" densities), as shown in figure 6 . The spectra were high-pass filtered using a cut off of $0.3(3300 \mathrm{~Hz})$ to suppress the sound introduced by the drive tractor, and visual comparisons were made among two depths and three treatments.

The left column of figure 6 plots represent experiments at $15 \mathrm{~cm}$ depth (above the hardpan) and since the dry bulk densities were similar among treatments $(1.16,1.19$, and $1.14 \mathrm{~g} / \mathrm{cm}^{3}$, from table 1), the signal FFTs were expected to be similar, which is confirmed in the graphs.

The right column plots represent experiments at $30 \mathrm{~cm}$, just below the hardpan location (in the "single pass" and "double pass" cases). From table 1, the dry bulk density increased from $1.18 \mathrm{~g} / \mathrm{cm}^{3}$ (no pass) to $1.47 \mathrm{~g} / \mathrm{cm}^{3}$ (single pass) to $1.65 \mathrm{~g} / \mathrm{cm}^{3}$ (double pass). The acoustic plots also show a visible increase in amplitude, especially around 0.6 $(6600 \mathrm{~Hz})$, which implies that the amplitude is a function of soil density.

A depth effect on the amplitude can be seen in the top row plots. Here, the depths are $15 \mathrm{~cm}$ and $30 \mathrm{~cm}$, but no hardpan was installed. Even without this external soil compression, an overall increase in amplitude is visible.

\section{VARIABLE-DEPTH EXPERIMENTS}

For the variable-depth experiments, the acoustic data were band-pass filtered with the frequency window values obtained from the constant-depth experiments $(0.57$ to 0.63 , or 6,300 to $7,000 \mathrm{~Hz})$. The cone index $(\mathrm{CI})$ data as a function 


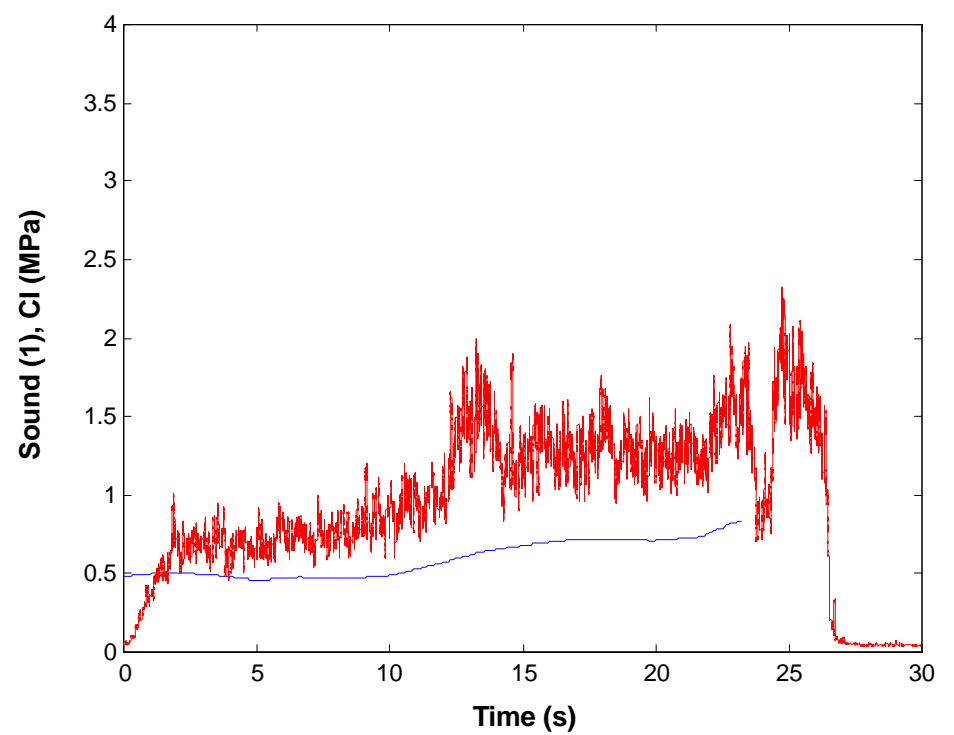

Figure 7. Cone index (solid line) and filtered acoustic data vs. time for variable-depth experiment under "no pass" density condition. The CI remaining low indicates no hardpan, and the acoustic signal shows a similar pattern as CI.

of depth were combined with the cone depth as a function of time, yielding $\mathrm{CI}$ as a function of time. The filtered acoustic data as a function of time were compared to the CI data as a function of time, as shown in figures 7 through 9. This procedure was repeated for the three density treatments (no pass, single pass, and double pass).

Figure 7 shows the CI and acoustic data for the "no pass" condition (no hard pan). The solid line represents the $\mathrm{CI}$ in this plot as a function of time. It is clear that the CI slightly increased due to the depth increase over time (at $30 \mathrm{~s}$ a depth of $30 \mathrm{~cm}$ was reached, see figure 3 ). The filtered sound amplitude showed a similar increase over time and depth. The distinct extremes in the sound data from approximately 12 to $14 \mathrm{~s}$ and at approximately $24 \mathrm{~s}$ are unexplained and may be caused by soil discontinuities, such as larger clumps or rocks.

Figure 8 shows the CI and acoustic data for the "single pass" experiment (hardpan at $25.4 \mathrm{~cm}$ ). Although the hard pan was intended and visualized as a narrow plane located at $25.4 \mathrm{~cm}$, the CI data show that it is much wider than expected. However, this does not compromise the comparison of acoustic measurements with CI data. From figure 8 , it is clear that the filtered acoustic data has the same overall shape as the CI data, although the relationship appears to be non-linear. In addition, there seems to be a time (depth) lag, which might be caused by the physical size of the cone $(30 \mathrm{~mm}$ diameter). The larger the cone size, the more the plow pan becomes smoothed in the data, since the sound generation is integrated over the whole area of the cone. In future experiments, the cone size should be as small as possible.

Figure 9 shows the CI and acoustic data for the "double pass" experiment (hardpan at $25.4 \mathrm{~cm}$ ). The hardpan starts and peaks at approximately the same location as in the "single pass" case (fig. 8), but it is more intense. The sound data are slightly higher in the hardpan range, and the contour is similar to the true hard pan CI. Again, a time (depth) lag

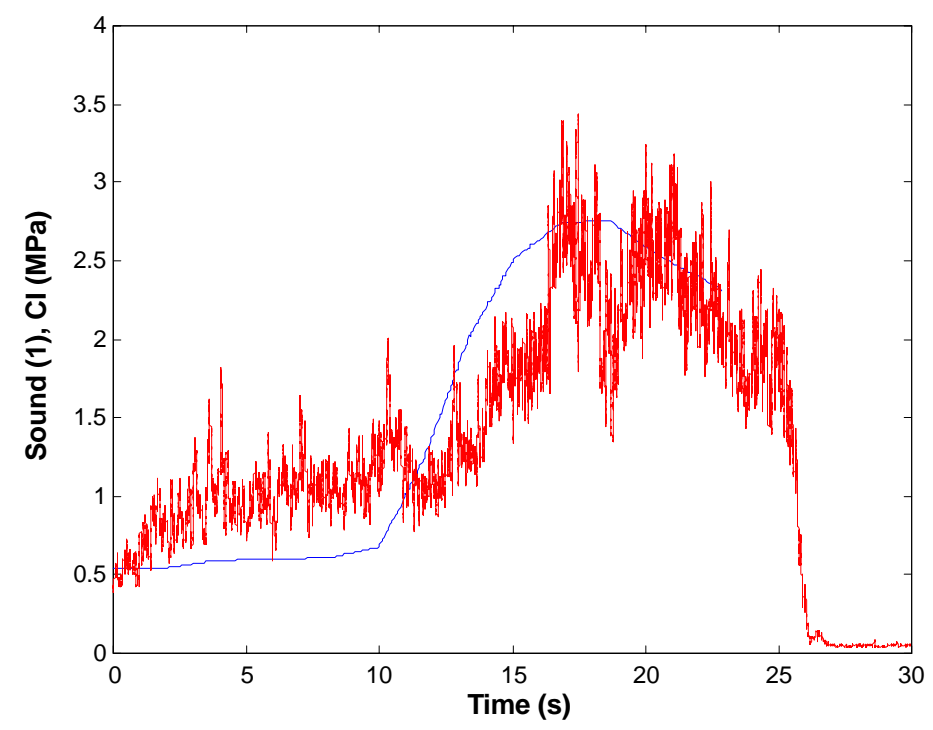

Figure 8. Cone index (solid line) and filtered acoustic data vs. time for variable-depth experiment under "single pass" density condition. The CI reaches a peak at the hardpan location, and the acoustic signal shows a similar pattern. 


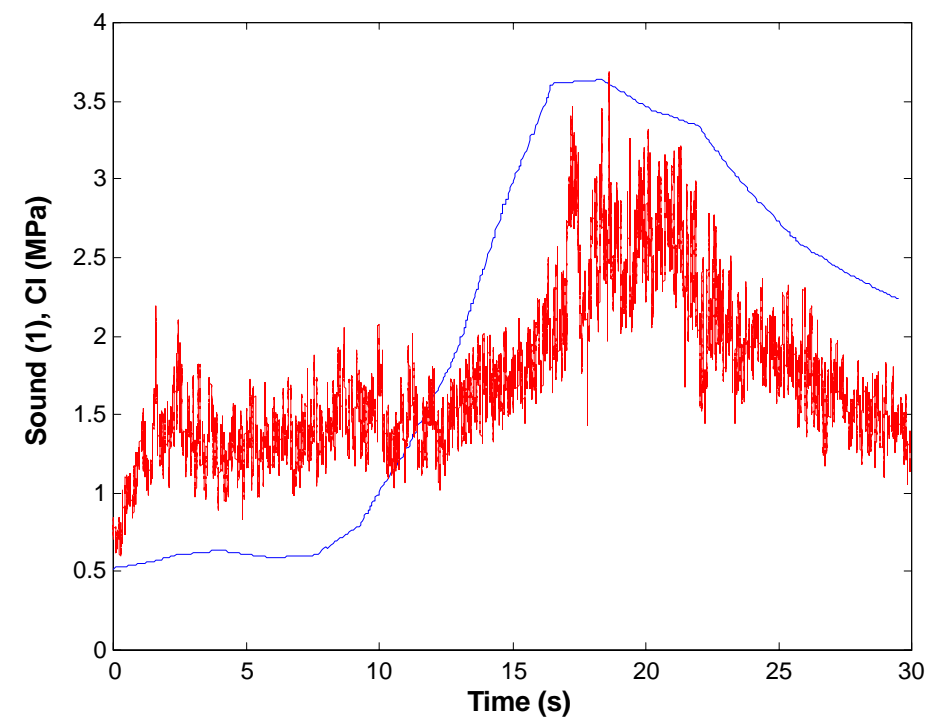

Figure 9. Cone index (solid line) and filtered acoustic data vs. time for variable-depth experiment under "double pass" density condition. The CI has a wider range and higher peak values, indicating a denser hardpan, and the acoustic signal shows a similar pattern.

is present, and there are some unexplained peaks (such as at $17 \mathrm{~s}$ ). These were attributed to true local variations in density caused by clumps or embedded objects.

\section{CONCLUSIONS}

An acoustic compaction layer detection system was developed using a microphone-fitted cone mounted on a tine. To observe the acoustic effects of depth and soil density, constant-depth experiments at 15 and $30 \mathrm{~cm}$ depth were conducted under three densities, "no pass" (no hardpan), "single pass" (single compression hardpan), and "double pass" (double compression hardpan).

Results showed that both soil depth and density had a detectable effect on the sound levels produced. In addition, the highest acoustic sensitivity to density was in the upper range of the frequency spectrum. This led to the conjecture that the soil-sensor interface introduces a low-pass filtering mechanism where the cutoff frequency depends on the level of the contact between medium and sensor. In other words, the higher-frequency signals are always present, but they do not transfer into the microphone due to the low-pass filtering effect of the soil-cone interface. The inherent low-pass filtering mechanism is an advantage. It allows detection of the location of the higher-density soil layers (hardpans) by only observing the highest frequency range of the signals (termed "detection edge"), as demonstrated in this research.

To test the system's potential for detecting hardpans, variable-depth experiments were carried out in which the cone gradually penetrated the soil from the surface downward until it passed the hardpan. The data were filtered using the detection edge range to isolate density effects. High levels of agreement were found between cone index measurements and associated sound levels, which clearly demonstrated the methods' potential to detect hardpans. Some unexplained peaks were encountered in the data that may be attributed to embedded dense objects.

In future research, experiments are needed among soil types and varying soil water levels. In addition, since the frequency content of the data varies over time, a wavelet analysis may be appropriate. Further fundamental research is needed to explain why the soil-cone interface forms a low-pass filtering mechanism for propagation of sound into the sensor.

\section{REFERENCES}

Adamchuk, V. I., M. T. Morgan, and H. Sumali. 2001. Application of a strain gauge array to estimate soil mechanical impedance on-the-go. Trans. ASAE 44(6): 1377-1383.

Al-Adawi, S. S., and R. C. Reeder. 1996. Compaction and sub-soiling effects on corn and soybean yields and soil physical properties. Trans. ASAE 39(5): 1641-1649.

ASAE Standards. 1999a. S313.3: Soil cone penetrometer. St. Joseph, Mich.: ASAE.

ASAE Standards. 1999b. EP542: Procedures for using and reporting data obtained with the soil cone penetrometer. St. Joseph, Mich.: ASAE.

Ayers, P. D., and J. V. Perumpral. 1982. Moisture and density effect on cone index. Trans. ASAE 25(5): 1169-1172.

Batchelor, J. A. 1984. Properties of bin soils. Auburn, Ala.: USDA-ARS National Tillage Machinery Laboratory.

Chung, S., and K. A. Sudduth. 2003. Characterization of soil strength data for an on-the-go sensor. ASAE Mid-Central Conference Paper No. MC03-203. St. Joseph, Mich.: ASAE.

Clark, R. L. 1999. Evaluation of the potential to develop soil strength maps using a cone penetrometer. ASAE Paper No. 993109. St. Joseph, Mich.: ASAE.

Fulton, J. P., L. G. Wells, S. A. Shearer, and R. I. Barnhisel. 1996. Spatial variation of soil physical properties: A precursor to precision tillage. ASAE Paper No. 961002. St. Joseph, Mich.: ASAE.

Hall, H. E., and R. L. Raper. 2005. Development and concept evaluation of an on-the-go soil strength measurement system. Trans. ASAE 48(2): 469-477.

Liu, W., L. D. Gaultney, and M. T. Morgan. 1993. Soil texture detection using acoustic methods. ASAE Paper No. 931015. St. Joseph, Mich.: ASAE.

MatLab. 2000. MatLab, ver. 6.0. Natick, Mass.: The Math Works, Inc.

Oelze, M. L., W. D. O’Brien, and R. J. Darmody. 2002.

Measurement of attenuation and speed of sound in soils. SSSA J. 66(3): 788-796. 
Oelze, M. L., J. M. Sabatier, and R. Raspet. 2003. Roughness measurements of soil surfaces by acoustic backscatter. SSSA. J. 67(1): 241-250.

Perumpral, J. V. 1987. Cone penetrometer applications - A review. Trans. ASAE 30(4): 939-944.

Raper, R. L., B. H. Washington, and J. D. Jarrell. 1999. A tractor-mounted, multiple-probe soil cone penetrometer. Applied Eng. in Agric. 15(4): 287-290.
Raper, R. L., E. B. Schwab, and S. M. Dabney. 2001. Measurement and variation of site-specific hardpans. ASAE Paper No. 011008. St. Joseph, Mich.: ASAE.

Raper, R. L., D. W. Reeves, J. Shaw, E. van Santen, P. Mask, and T. E. Grift. 2003. Reducing draft requirements and maintaining crop yields with site-specific tillage. In Proc. 16th International Soil Tillage Research Organization (ISTRO) Conference, 961-965. Brisbane, Australia.

Utset, A., and G. Cid. 2001. Soil penetrometer resistance spatial variability in a ferrasol at several soil moisture conditions. Soil Till. Res. 61(3): 193-202. 